\title{
GESTÃO PÚBLICA MUNICIPAL E PARTICIPAÇÃO DEMOCRÁTICA NO BRASIL ${ }^{1}$
}

\author{
Carlos Vasconcelos Rocha
}

\begin{abstract}
RESUMO
O trabalho aborda três casos de participação democrática em administrações municipais do estado de Minas Gerais, quais sejam: os Conselhos Gestores de Saúde, nos municípios de Bom Despacho e Lagoa da Prata, e os Centros de Encontro e Integração de Ações (CEIA), no município de Betim. Nas últimas décadas, a participação política tem se caracterizado por uma crescente presença da sociedade civil na definição de políticas públicas. Assim, institucionalizam-se espaços em que atores da sociedade civil e atores estatais participam em diversas áreas de decisão de políticas sociais. Parte substantiva da literatura aposta nas virtudes democráticas da participação. Este trabalho, no entanto, busca apontar uma série de problemas que afetam a institucionalização da democracia participativa. Os resultados dos casos abordados aqui demonstram que os experimentos analisados não indicam uma evolução da democracia brasileira, conforme as promessas iniciais. No geral, o grau de participação efetivamente verificado está aquém do desejado pelos defensores da democracia participativa, já que o critério de medida geralmente adotado é um padrão ideal dificil de ser concretizado. Contudo, se olhamos a trajetória histórica recente de nossas instituições democráticas, a definição de espaços de deliberação pela sociedade civil, apesar dos seus problemas, tem potencial inegável de reforçar a accountability do poder público, aumentando a transparência de suas ações.
\end{abstract}

PALAVRAS-CHAVE: democracia participativa; administração municipal; políticas públicas.

\author{
“Oh! A estranha cidade, tão vasta e tão vazia! \\ Imensos boulevards, abertos para multidões, mas \\ silenciosos desertos! [...] Vasta catedral que os fiéis \\ não chegam a encher! Há de povoar-se um dia a \\ cidade da fé e da esperança" \\ (Hazard apud GRAVATÁ, 1982).
}

\section{INTRODUÇÃO}

A observação transcrita em epígrafe, que o historiador Paul Hazard fez sobre a cidade de Belo Horizonte no ocaso dos anos 1920, pode muito bem servir de metáfora para a profusão de espa-

\footnotetext{
1 Agradeço a ajuda da Fundação de Amparo à Pesquisa do Estado de Minas Gerais (Fapemig), que financiou a pesquisa da qual se originou parte deste artigo, bem como a Coordenação de Aperfeiçoamento de Pessoal de Nível Superior (Capes), que me proporcionou uma bolsa de pósdoutoramento, fundamental para a conclusão deste trabalho. Agradeço também os comentários dos pareceristas anônimos da Revista de Sociologia e Política pelas suas valiosas contribuições.
}

ços de participação da sociedade civil nas decisões públicas criados, no Brasil, nas últimas décadas. Os céticos diriam que esses espaços simulam "catedrais sem fiéis": espaços de participação que não encontram resposta em cidadãos ativos, capazes de extrair todas as possibilidades da nova institucionalidade democrática. Uma imagem que contrasta com a "fé" dos que vêem a democracia participativa como panacéia para todos os problemas. Essa polarização de expectativas está marcadamente presente nos debates sobre o tema da democracia participativa. No entanto, o esforço de compreensão da realidade exige ultrapassar tanto o ceticismo temerário como o otimismo temerário. 
De fato, o recente processo de democratização política no Brasil foi caracterizado pela notável capacidade de mobilização de diversos setores da sociedade civil, que reivindicavam seu direito de participação política. Para além das instituições da democracia representativa, atores filiados a correntes ideológicas diferenciadas demandavam a adoção de espaços compartilhados de deliberação sobre decisões de políticas públicas entre a sociedade civil e o poder público. Defendiam, cada qual com ênfases e argumentos específicos, que a descentralização relacionar-se-ia positivamente com democracia, eficiência e inovação na gestão pública.

Essas reivindicações acabaram se concretizando em uma variedade de experiências participativas. A Constituição Federal de 1988, ao definir a obrigatoriedade da adoção de espaços de participação em diversas áreas de políticas públicas, é expressão dessa tendência. Assim, nas últimas décadas, temos a difusão de experiências de democracia participativa nos diversos níveis de governo. Os governos da União e dos estados implementaram espaços de participação, mas foram nos municípios que essas experiências disseminaram-se de maneira mais inovadora ${ }^{2}$. Seja por exigência constitucional, seja pela decisão e criatividade dos atores locais, a consolidação de tais experiências torna-se aspecto central da institucionalização democrática brasileira recente.

Porém, entre as intenções e os fatos, um longo caminho se fez presente. Aquelas esperanças iniciais de democratização e de eficiência acabaram se defrontando com as dificuldades surgidas no processo de consolidação desses espaços de participação. A distância que separa o que se almejou do que se efetivamente alcançou é algo a ser mensurado: o esforço de se avaliar o efetivo funcionamento dos diversos mecanismos de democracia participativa adotados nas últimas décadas é ainda incipiente. E como avaliar envolve necessariamente alguma referência valorativa, deve-se evitar descartar tais experiências quando elas não se aproximam de um ideal muitas vezes impossível de ser atingido. Mais do que adotar posições excessivamente normativas, é necessário avaliar em que medida esses espaços participativos cumprem os seus objetivos e quais

\footnotetext{
2 Ver, por exemplo, registros de várias experiências inovadoras em Fundação Getúlio Vargas (2010).
}

os motivos explicam seus sucessos e insucessos. Este trabalho pretende, de maneira não exaustiva, relacionar alguns pressupostos teóricos com algumas evidências empíricas, a fim de fornecer pistas para a análise do desempenho da participação nos marcos da democracia recente.

Em sua primeira parte, o trabalho irá recuperar brevemente o debate sobre a democracia participativa, apontando tanto os argumentos favoráveis como as ponderações críticas levantadas por diversos autores. Numa segunda parte, pretendemos problematizar tal debate a partir do estudo de experiências desenvolvidas em três municípios do estado de Minas Gerais, quais sejam: os Conselhos Gestores de Saúde, nos municípios de Bom Despacho e Lagoa da Prata, e os Centros de Encontro e Integração de Ações (CEIA), no município de Betim. Finalmente, buscaremos sugerir algumas questões relativas aos resultados da adoção desses espaços de participação democrática, com base em evidências extraídas da análise dos casos selecionados.

\section{DEMOCRACIA, PARTICIPAÇÃO E PODER LOCAL}

Nas últimas décadas do século XX, como aspecto central da reforma do Estado, diferentes correntes de orientação política defendem em diversos países a descentralização político-administrativa do aparato estatal. Por exemplo, de 75 países em desenvolvimento, 63 adotaram reformas descentralizantes (ARRETCHE, 1996). Nesse processo, com argumentos diferentes, atores de variadas filiações ideológicas sustentam a necessidade de reformar as instituições estatais segundo o princípio da descentralização e da participação. Especialmente por parte de setores da esquerda, a criação de espaços de deliberação implicaria a democratização do processo de tomada de decisões em áreas de políticas públicas específicas. $\mathrm{O}$ desenvolvimento da democracia pressupõe, nesse sentido, o fortalecimento das instituições políticas locais, por viabilizarem a participação dos cidadãos nas decisões públicas. E fortalecer institucional e politicamente esses espaços de participação implicaria criar condições para a superação de problemas advindos do Estado centralizado, a saber: balcanização do poder público por elites econômicas e políticas; exercício de um poder ilegítimo da burocracia pública no processo de tomada de decisões; e o clientelismo como lógica de ação do Estado. 
A ampliação dos espaços de participação possibilitaria, também, a vocalização de setores excluídos social, econômica e politicamente, ensejando a adoção de políticas redistributivas. Ou seja, imaginava-se que inclusão política redundaria também em inclusão econômica. Além disso, o exercício da participação implicaria educação para a cidadania, propiciando o desenvolvimento de virtudes cívicas, ensejando maior e melhor capacidade de participação da população no espaço público.

De outro lado, os setores mais à direita, representados principalmente por instituições como o Banco Mundial, relacionam descentralização e participação com maior eficiência e eficácia da ação pública. Instituir espaços de participação da sociedade civil no processo de tomada de decisões potencializaria a eficiência das ações públicas, neutralizando os interesses corporativos da burocracia e as barganhas clientelistas, possibilitando a adequação das decisões às reais demandas da sociedade e a articulação de maneiras mais efetivas de fiscalização das ações governamentais. A proximidade entre a administração pública e a sociedade civil implicaria maior accountability e responsiveness.

Tais argumentos sustentam, portanto, que a realização dos ideais democráticos e de eficiência dependem da escala em que se processam as decisões políticas: haveria, assim, por um lado, uma relação positiva entre descentralização, democracia e eficiência; e, por outro lado, em sentido inverso, uma afinidade entre centralização, autoritarismo e ineficiência. Entretanto, em que pesem tais esperanças, os resultados da implementação dessas reformas sugerem que não há uma afinidade necessária entre esses valores.

Mais que isso, hoje, com um maior discernimento fornecido pelo passar dos anos, pode-se dizer que, até meados dos anos 1990, a literatura sobre o tema da reforma do Estado era marcada por uma ênfase exageradamente normativa, e até certo ponto ingênua, na defesa da descentralização como panacéia para os problemas da democracia e da gestão pública. No entanto, essa é ainda uma percepção genérica do fenômeno, pois é patente a necessidade de se aprofundar o exame do padrão concreto de relação entre o Estado e a sociedade civil, visando a aquilatar os efetivos resultados do processo de reforma institucional.
Como parte desse esforço, os estudos que estão sendo desenvolvidos vão problematizar a questão da reforma do Estado a partir de duas perspectivas: uma que se volta para as características da sociedade civil; e outra que centra a atenção nas características das instituições. O sucesso da implementação dos espaços de participação dependeria, no primeiro caso, dos atributos cívicos da sociedade civil e, no segundo caso, de características adequadas das instituições públicas.

A abordagem da questão da participação pela ótica da sociedade civil dá relevância ao conceito de "capital social”. Coleman (1988) é um dos precursores dessa perspectiva analítica ao estabelecer o princípio de que a "otimização" do capital físico-econômico e humano é maior quando as relações de confiança e reciprocidade aumentam em uma comunidade. Nessa linha de pensamento, Putnam, em trabalho sobre a Itália que se tornou clássico, propõe uma interpretação culturalista para a explicação dos fundamentos do "bom governo". Para ele, em todas as sociedades o dilema da ação coletiva obsta as tentativas de cooperação para benefícios mútuos. A cooperação voluntária dependeria do capital social, que diz respeito "a características da organização social, como confiança, normas e sistemas que contribuam para aumentar a eficiência da sociedade, facilitando as ações coordenadas" (PUTNAM, 1996, p. 177). Ele afirma que o capital social instaura um círculo virtuoso que "redunda em equilíbrios sociais com elevados níveis de cooperação, confiança, reciprocidade, civismo e bem-estar coletivo" (idem, p. 186-187). Ao contrário, a comunidade não-cívica instaura um círculo vicioso: "A deserção, a desconfiança, a omissão, a exploração, o isolamento, a desordem e a estagnação intensificamse reciprocamente" (ibidem). Segundo ele, as sociedades horizontais, com maior igualdade, caracterizam-se por maior grau de engajamento cívico. Portanto, nessa perspectiva, a qualidade de um governo local relaciona-se com a presença de um substrato cultural de capital social.

Dentre as diversas variações que essa abordagem comporta, vale, para nossos fins - já que diz respeito a uma característica relevante dos casos considerados neste trabalho -, fazer referência a uma específica. Alguns autores afirmam que o fator de gênero influencia a existência de capital social, na medida em que as mulheres teriam maior propensão a comportamentos interdependentes, buscando soluções compartilhadas para os pro- 
blemas, enquanto os homens seguiriam uma justiça individual baseada numa moral de direitos (Folbre apud ABU-El HAJ, 1999). Assim, resultados cooperativos seriam mais prováveis em grupos com maior participação de mulheres.

$\mathrm{Na}$ outra perspectiva, o foco de análise voltase para as características das instituições políticas, que, ao cabo, explicariam a qualidade de uma democracia. Em uma de suas variantes, afirmase que a chave do sucesso de ações públicas eficientes dependeria da existência de uma burocracia pública autônoma, coesa, coerente, disciplinada, tecnicamente preparada e com esprit de corp. Segundo Evans (1996), a falta de participação da sociedade deve-se à vigência de instituições autoritárias e à ausência de horizontalidade social. Em sociedades cujas instituições públicas caracterizam-se pelo autoritarismo, coerção e clientelismo, a mobilização do poder local torna-se difícil e as experiências bem-sucedidas não se generalizam. Dessa forma, o Estado, como fator ativo de mobilização social e incentivador de redes cívicas, acaba por determinar o sucesso das iniciativas de participação.

Nesse sentido, Fox (1996) também estabelece uma relação entre a participação e o caráter das instituições e dos dirigentes políticos. Para ele, a participação da sociedade civil viabiliza-se quando as instituições públicas são dirigidas por grupos reformistas favoráveis à intervenção política construtiva do Estado, comprometidos com a história de luta dos atores sociais e, ao mesmo tempo, capazes de propor soluções pragmáticas aos problemas existentes. Para tal, essas lideranças políticas deveriam combinar um passado utópico com a experiência de derrotas, derrotas estas fundamentais para emprestar-lhes certo pragmatismo. $O$ fator essencial para a generalização de experiências de sucesso na mobilização do capital social seria, portanto, a presença de elites governamentais reformistas, comprometidas com a valorização de experiências de democracia participativa. Como se pode notar há uma forte relação entre as características requeridas para as elites políticas expostas acima e a trajetória de atores vinculados à esquerda do espectro político.

Tomando essas duas perspectivas - as que enfatizam as características da sociedade civil e as que centram atenção nas instituições -, poderíamos demarcar como ponto de partida a proposição de que há razão na afirmação de que a visão do capital social é determinista, condenando uma variedade de países sem cultura cívica a uma situação sem saída, e minimizando assim o papel das instituições. Evans (1996), por exemplo, critica o determinismo das teses de Putnam, argumentando que se capital social é cultura, e se esta é constituída a partir de um longo processo histórico, a maioria dos países poderia desistir da civilidade. Contudo, por outro lado, poderíamos também considerar a crítica oposta de que o enfoque institucional não atenta para as condições sociais subjacentes à institucionalização. Imaginar que as instituições podem apresentar um bom desempenho sem algum substrato de cultura cívica é algo logicamente pouco adequado. Catedrais certamente requerem fiéis. Assim, as duas dimensões devem ser vistas como partes de um todo e, nesse sentido, o esforço analítico deve atentar para as características e processos que se desenvolvem nas esferas da sociedade civil e das instituições.

Porém, para além do debate sobre os fundamentos das duas perspectivas analíticas consideradas, a própria relação positiva entre a ampliação dos espaços de participação da sociedade civil junto ao poder público e a democracia é questionada por um conjunto de outros autores. Especificamente, postula-se que a participação de setores da sociedade nos processos de decisão poderia implicar democratização, mas também redundar em seu oposto. As formas associativas não se distribuem geográfica e socialmente de maneira uniforme, pois expressam padrões de desigualdade na distribuição do poder: o capital social é geralmente propriedade de grupos e estratos sócio-econômicos bem definidos. Por exemplo, a educação seria um requisito para o capital social, e ela está concentrada nas elites. Assim, em sociedades diferenciadas, o capital social pode contribuir para a manutenção do statu quo, já que pode se relacionar positivamente com a estratificação social e com as desigualdades federativas. A crítica de fundo dessa linha de argumentação é que o tema do poder acaba ficando excluído do debate sobre capital social e essa omissão é evidentemente problemática, no sentido de que qualquer vigor participativo é tomado como positivo.

Em artigo primoroso, Whitehead (1999) desenvolve essa linha argumentativa. Ele afirma que, muitas vezes, "máfias" - ou seja, associações particularistas e intolerantes que reivindicam privilégios em detrimento de terceiros - atuam no contexto da democracia, substituindo ou subver- 
tendo formas mais universalistas de participação. Mesmo os direitos legais, como segurança e justiça, que são formalmente uniformes, são de fato seletivamente distribuídos. $\mathrm{O}$ acesso a esses direitos pode depender da posição de classe, da raça e da origem familiar. A capacidade associativa tende, portanto, a concentrar-se em uma minoria da população que tem origem privilegiada na estrutura de poder pré-democrática. Sendo assim, conforme observa o autor, "qualquer que tenha sido o caminho histórico seguido, os padrões resultantes de vida associativa e comunicação social serão altamente estruturados, com setores tradicionalmente mais favorecidos e centrais e outros marginalizados e excluídos. Dependendo da localização de cada pessoa nessa estrutura de privilégios e oportunidades, e do grau de abertura e flexibilidade do sistema, é possível considerar a sociedade civil resultante tanto como expressão mais autêntica e a garantia durável de uma democracia política, quanto a mais flagrante negação de sua promessa universalista" (WHITEHEAD, 1999, p. 21).

Considerados esses argumentos, a relação entre sociedade civil e democracia torna-se bastante complexa. Se existe mais de uma via histórica para o estabelecimento da sociedade civil, certamente haverá formas diferenciadas de seu envolvimento na construção da democracia. Fazendo referência às ênfases na cultura política e nas instituições, respectivamente, a democracia pode ser tanto fruto da sociedade cívica como esta pode ser resultado das instituições democráticas. Tanto a democracia política pode fortalecer atores políticos que agem contra a existência de uma sociedade civil robusta, fundada na capacidade de deliberação autônoma de seus membros, como, por outro lado, a sociedade civil pode afetar a democracia em uma série de formas negativas: pode levar a uma distribuição de influência tendenciosa no processo de produção de políticas públicas e pode, no contexto de uma pluralidade de sociedades civis atuando dentro da mesma comunidade política, provocar a exclusão de grupos constituídos a partir de identidades étnicas, culturais e lingüísticas.

Além do mais, os fatos parecem demonstrar que a participação não é algo que se desenvolve de forma cumulativa. Antes disso, a participação parece ser cíclica. A sociedade civil sempre será pressionada por "externalidades", ou efeitos nãopretendidos, de processos políticos, socioeco- nômicos (desemprego, criminalidade e supremacia do mercado) e tecnológicos (com a televisão e Internet, por exemplo, afastando as pessoas do convívio no espaço público) ou por fatores intencionais, como a ação do Estado e/ou da sociedade antiliberal. Exemplo disso é que a notável mobilização de diversos setores da sociedade civil brasileira, nos anos 1980, refluiu nas décadas seguinte.

Estabelecidas essas referências teóricas, faremos uma reflexão sobre algumas experiências de implementação de espaços de participação social em três municípios de Minas Gerais.

\section{REFLEXÕES A PARTIR DEALGUMAS EX- PERIÊNCIAS DE DEMOCRACIA PARTICI- PATIVA}

Nas últimas décadas, uma profusão de experiências de democracia participativa foi desenvolvida pelos municípios brasileiros. Conselhos deliberativos de políticas sociais, orçamento participativo, gestão participativa de escolas públicas e diversas outras modalidades de espaços de participação foram desenhando o perfil das instituições públicas brasileiras. Em grande medida, direta ou indiretamente, isso se deveu à ação de partidos de esquerda. Um ator central nesse processo foi o Partido dos Trabalhadores (PT), criado em 1980, que hegemoniza a aglutinação dos setores organizados da sociedade civil e assume a defesa da democracia participativa ${ }^{3}$. Ao lograr êxito em várias eleições para diversos governos municipais, antes de alcançar a presidência da República, o PT empenha-se na difusão de gestões participativas e utiliza-se disso como marca do partido junto ao eleitorado. Se o partido não monopoliza a defesa de instituições participativas, podemos dizer que, em conjunto com outros partidos menores de esquerda, é protagonista na institucionalização de espaços de participação da sociedade civil em decisões públicas.

O resultado dessas experiências é, hoje, objeto de diversos estudos. Contudo, não há ainda consenso suficiente sobre em que medida as pro-

\footnotetext{
3 Com o colapso do socialismo real, a defesa da democracia participativa passa a substituir, para parte da esquerda, a defesa do socialismo. Sem entrar em detalhes, é interessante notar como algo que antes era tido como "mera" formalidade para a esquerda - no caso, as instituições democráticas - passa a ocupar um lugar central no seu discurso.
} 
messas iniciais foram cumpridas. Visando a fornecer uma contribuição para o entendimento do efetivo funcionamento desses espaços de participação, tomaremos como referência três experiências desenvolvidas em municípios do estado de Minas Gerais. Duas dessas experiências referemse aos conselhos municipais de saúde dos municípios de Lagoa da Prata e Bom Despacho. A abordagem desses dois casos permite estabelecer uma comparação entre municípios com tradições políticas diferenciadas: o primeiro caracterizado por uma sociedade civil mais vigorosa e pela hegemonia política do PT; o segundo caracterizado por uma sociedade civil mais assimétrica, com hegemonia de partidos mais conservadores. Posteriormente, abordaremos a experiência do projeto Centro de Encontro e Integração de Ações (CEIA), desenvolvido no município de Betim. Esse projeto foi concebido e implementado por um governo do PT e apresentou um desenho peculiar e inovador em relação a outras experiências adotadas no país ${ }^{4}$.

\section{III.1. Os conselhos de saúde em Bom Despacho e Lagoa da Prata}

Uma estratégia de desenvolvimento da democracia participativa no Brasil foi a criação de conselhos gestores de políticas públicas de caráter deliberativo. Aspecto central da descentralização das políticas públicas, os conselhos foram criados, tanto nos estados como nos municípios, em diversas áreas das políticas sociais, como saúde, educação, assistência social, habitação, criança e emprego, por obrigatoriedade do texto constitucional brasileiro promulgado em 1988. Os municípios, especificamente, passaram a criar os conselhos gestores nas áreas sociais como requisito para o recebimento de recursos financeiros do governo central.

Segundo Tatagiba (2002, p. 54), os "conselhos gestores de políticas públicas são espaços públicos de composição plural e paritária entre Estado e sociedade civil, de natureza deliberativa, cuja função é formular e controlar a execução das políticas públicas setoriais". Os conselhos foram

4 Os dois primeiros casos foram estudados em Oliveira (2005) e o último, em Lima (2003). Ambos os trabalhos foram dissertações de mestrado orientadas pelo autor deste artigo. Os dados levantados nesses trabalhos são aqui utilizados sem, contudo, reproduzir suas conclusões. Estas são da responsabilidade de quem assina este artigo. criados visando a possibilitar a inclusão de amplos setores sociais nos processos de decisão pública, fornecendo condições para o fortalecimento da cidadania e para o aprofundamento da democracia. Sua composição deve incorporar representantes do governo e da sociedade civil, sendo que a indicação se faz, no primeiro caso, pelo chefe do poder Executivo, seja estadual ou municipal, e, no segundo caso, pelos pares de cada segmento representado da sociedade civil, conforme legislação de cada área de política específica.

No entanto, como ressalta Dagnino (2002), o potencial democratizante dos conselhos mostrouse diferenciado, dada as condições de cada caso específico. Ao lado do ideal democratizante dos conselhos, uma realidade prática muito mais problemática surgiu. Em muitos municípios sem tradição associativa e com uma configuração de poder bastante assimétrica, os conselhos limitam-se a cumprir formalidades, quando não são manipulados pelas elites locais. Outros estudos demonstram também a incidência de problemas como heterogeneidade do nível da capacitação dos conselheiros e fragmentação do segmento da sociedade civil, muitas vezes composta por grupos diversificados e antagônicos, redundando em assimetrias de participação entre os interesses representados no interior dos conselhos. O processo decisório, não raro, mostra-se mais favorável aos setores governamentais e aos segmentos mais poderosos da sociedade civil. Nesse sentido, por exemplo, Tatagiba (2002) demonstra que assuntos pontuais predominam na agenda dos conselhos em detrimentos das questões estruturais, fruto, em boa medida, da capacidade de controle da burocracia pública sobre a agenda temática dos conselhos. Os governos muitas vezes adotam estratégias de esvaziamento desses espaços e, não raro, instrumentalizam os conselhos para seus objetivos específicos.

Considerando os conselhos de saúde de Bom Despacho e Lagoa da Prata ${ }^{5}$, uma questão a ser respondida é em que medida esses espaços realmente "democratizam a democracia", segundo expressão utilizada por Santos (2002), ou, ao contrário, configuram-se em mecanismos de decisão meramente formais, legitimando as decisões de grupos políticos dominantes.

5 Esse tópico baseia-se em dados levantados em Oliveira (2005). 
Como se sabe, a área da saúde, fundamental na produção do bem-estar social, é onde os conselhos encontram-se mais consolidados no Brasil. A oferta dos serviços de saúde é função privilegiada dos municípios e estes só recebem repasses de recursos financeiros do Sistema Único de Saúde (SUS) se os seus conselhos estiverem implementados. A Lei Federal n. 8 142, de 28 de dezembro de 1990, define a participação da comunidade na gestão das políticas de saúde da seguinte forma: "O Conselho de Saúde, em caráter permanente e deliberativo, órgão colegiado composto por representantes do governo, prestadores de serviço, profissionais de saúde e usuários, atua na formulação de estratégias e no controle da execução da política de saúde na instância correspondente, inclusive nos aspectos econômicos e financeiros" (BRASIL, 1990). Os conselhos de saúde apresentam uma especificidade em sua composição em relação a conselhos de outras áreas de políticas sociais: a representação dos usuários deve ser paritária em relação aos demais segmentos.

A avaliação do funcionamento dos conselhos de saúde nos dois municípios foi realizada a partir das seguintes variáveis: representatividade dos conselheiros; autonomia dos mesmos no processo de tomada de decisões; e eficácia da participação em termos de resultados nas políticas públicas.

Bom Despacho e Lagoa da Prata têm, respectivamente, 39943 e 38758 habitantes (INSTITUTO BRASILEIRO DE GEOGRAFIA E ESTATÍSTICA, 2000), sendo bastante representativos do perfil da totalidade dos municípios brasileiros no que tange ao aspecto populacional: dos 5507 municípios brasileiros, $90 \%$ possuem população inferior a 50000 habitantes.

As tradições políticas e culturais das duas cidades, no entanto, apresentam diferenças significativas, apesar da sua proximidade geográfica e da mesma dimensão populacional. Em Bom Despacho, a sociedade civil é mais oligárquica, rural e conservadora. Já Lagoa da Prata caracteriza-se por uma cultura mais democrática, urbana e progressista. Por exemplo, o primeiro município tem a atuação de uma Igreja Católica conservadora e a presença de uma Vila Militar, com um grande contingente da população formada por militares e suas famílias, difundindo, de alguma forma, noções de ordem e hierarquia próprias dessas corporações. Lagoa da Prata, ao contrário, tem a presença de uma Igreja progressista ativa e inspirada pela Teologia da Libertação e de um combativo sindicato de trabalhadores rurais.

Essas diferenças expressam-se, também, no perfil político-eleitoral dos dois municípios. Em Lagoa da Prata, na última década, partidos mais à esquerda consolidaram-se na liderança política do município, especialmente o PT, que elegeu prefeitos e maiorias no poder Legislativo municipal. Os partidos mais à direita, por sua vez, predominam em Bom Despacho ${ }^{6}$. O caráter mais progressista dos governos de Lagoa da Prata está presente, por exemplo, na adoção do orçamento participativo, experiência que caracteriza a gestão de partidos de esquerda, notadamente o PT, no Brasil.

Dadas essas características, poderíamos supor que as instituições participativas seriam mais efetivas em Lagoa da Prata, já que encontramos aí os requisitos apontados seja pelos defensores da tese do capital social, seja pelos defensores da tese institucionalista. Ou seja, sua sociedade civil apresenta maior capacidade organizativa e relações mais horizontalizadas, além de eleger governos de um partido fortemente comprometido com a gestão participativa. Em outras palavras, seu maior "capital social" e o caráter progressista de seus governos implicaria instituições públicas mais eficientes e mais democráticas, se corretas as teses focadas na sociedade civil e nas instituições expostas anteriormente.

Contudo, não é o que parece ocorrer, pelo menos de maneira suficientemente significativa. Apesar das diferenças ressaltadas, a avaliação dos conselhos de saúde em ambas as cidades aponta a ocorrência de problemas similares, como baixa representatividade dos conselheiros, denotando fragilidade dos vínculos com suas bases, e pouca autonomia dos representantes da sociedade civil no processo de tomada de decisões, especialmente dos representantes dos usuários do sistema de saúde, face à hegemonia dos representantes dos conselheiros governamentais. Vejamos mais detidamente, portanto, os seguintes aspectos dessas experiências: representatividade dos conselheiros em relação às suas bases; relação entre o perfil

\footnotetext{
6 Na década de 1990, o PT elegeu dois prefeitos e oito vereadores em Lagoa da Prata e apenas dois vereadores em Bom Despacho.
} 
sócio-econômico da sociedade e dos representantes da sociedade civil nos conselhos; índice de participação dos conselheiros em outras organizações da sociedade civil; dinâmica do funcionamento dos conselhos.

Em relação ao aspecto da representatividade, o que está em questão é se a atuação dos conselheiros implica de fato fazer valer os interesses dos seus representados no espaço do conselho. Em princípio, partindo dos critérios de escolha das entidades participantes dos conselhos, em ambos os municípios $74 \%$ delas foram escolhidas em conferências ou fóruns municipais de saúde, o que demonstra ampla participação e legitimidade dos escolhidos. Nesse quesito, Lagoa da Prata demonstra maior autonomia dos setores da sociedade civil em relação ao governo, bem como maior relação dos conselheiros com suas bases, já que $78 \%$ de suas entidades foram escolhidas de forma participativa, contra $69 \%$ de Bom Despacho. O restante das entidades foi escolhido, em ambos os casos, pelo Prefeito ou pelo Secretário de saúde (OLIVEIRA, 2005, p. 71).

No entanto, considerando essa relação de maneira mais qualitativa, o vínculo dos conselheiros com suas bases é frágil, pois as evidências demonstram que eles agem de forma individual, sem debater os assuntos e sem mesmo transmitir informações para seus representados.

Uma das promessas mais alardeadas da adoção dos espaços de participação foi sua capacidade de incorporar setores sociais desfavorecidos nos processos de decisão. Porém, nos casos em exame, o perfil sócio-demográfico dos conselheiros não é representativo do perfil da população municipal em geral. Na verdade, as elites de ambos os municípios são sobre-representadas nos conselhos. Vários segmentos sociais como pobres, negros, jovens, analfabetos, desempregados e evangélicos - não estão presentes nos espaços dos conselhos proporcionalmente à sua presença na população. Por exemplo, 59\% dos conselheiros de ambos os municípios possuem escolaridade média e alta em sociedades caracterizadas por baixa escolaridade, e $56 \%$ dos conselheiros têm mais de 40 anos - este número chega a $87 \%$ no segmento dos usuários -, em sociedades predominantemente jovens (idem, p. 61-64).

Por outro lado, os índices de participação e filiação dos conselheiros de ambos os municípios em sindicatos, partidos e outros órgãos comuni- tários apresentam variações. Nesse aspecto, a população de Lagoa da Prata demonstra maior capacidade de mobilização. Os índices de sindicalização dos conselheiros são semelhantes em Bom Despacho e Lagoa da Prata: respectivamente, $38 \%$ e $36 \%$. Porém, em Lagoa da Prata, $64 \%$ dos conselheiros são filiados a partidos políticos, contra apenas $8 \%$ do outro município, e $83 \%$ dos representantes dos usuários tem filiação partidária, em sua quase totalidade no PT. Esses dados indicam que a capacidade de participar pode ser concentrada em alguns grupos que acabam monopolizando o acesso aos espaços de participação, conforme afirmação de Whitehead (1999) exposta anteriormente. No caso, pode-se perceber uma evidência de que o conselho de Lagoa da Prata seria instrumentalizado pelo PT, violando o princípio democrático de pluralidade dos espaços participativos.

Os conselhos, sob certo aspecto, são concebidos como espaços em que a pluralidade dos interesses estabelece dialogicamente consensos. No entanto, $56 \%$ dos conselheiros de ambos os municípios não percebem a existência de grupos de interesse nos conselhos, o que denota a pouca percepção desse espaço, pelos seus componentes, como um local de embate de interesses. Isso explica o fato de que a maioria das deliberações é tomada por unanimidade, indicando baixa capacidade de contraposição de interesses.

Além disso, os dados demonstram uma baixa percepção de eficácia dos conselhos como espaços de deliberação, ainda que a discrepância seja considerável entre os dois municípios. A percepção dos conselheiros é de que sua atuação tem um caráter meramente informativo e consultivo, e muito pouco deliberativo. Por exemplo, $8 \%$ dos conselheiros de Bom Despacho percebem como alto o número de deliberações do conselho, ao passo que em Lagoa da Prata esse número sobe para $43 \%$, que, diga-se de passagem, é um percentual ainda baixo, mas alto em comparação com o primeiro município (OLIVEIRA, 2005, p. 101-102)

Em ambos os municípios, parte relevante dos assuntos tratados no conselho são definidos sem maior planejamento e discussão, falta capacitação aos conselheiros e várias das decisões tomadas não são implementadas pelo governo municipal. Apesar disso, contrariando a tendência positiva em favor de Lagoa da Prata apresentada nos ou- 
tros quesitos, apenas em Bom Despacho há registros de cobranças feitas pelos conselheiros aos gestores municipais, no sentido da homologação das decisões do conselho.

A análise da dinâmica de funcionamento dos conselhos mostrou, ainda, que o grau de participação (número de intervenções e índice de presença) é correlacionado positivamente com o nível educacional dos conselheiros. Mas a variável que mais incide sobre o grau de participação é a vinculação dos conselheiros ao setor público e aos prestadores de serviços. Esses setores, mesmo que estejam representados numericamente em inferioridade em relação aos representantes dos usuários dos serviços de saúde, acabam tendo maior capacidade de representar seus interesses.

$\mathrm{O}$ acesso dos conselheiros às informações relativas à política de saúde é baixo, no geral, com vantagens para os representantes do poder público. Sendo assim, a composição da pauta é freqüentemente definida pelo Presidente do conselho e pelo Secretário municipal de saúde, sem maiores debates. Com a hegemonia dos representantes estatais, pode-se inferir que há alto grau de controle dos conselhos pelos governos municipais.

Os conselhos, no limite, não definem as políticas municipais de saúde. Trabalham com uma visão fragmentada da saúde, deliberando sobre questões limitadas e secundárias. A maioria das questões tratadas no âmbito dos conselhos não é estruturante do setor: com indicadores bastante próximos entre os dois municípios, cerca de $65 \%$ dos assuntos tratados são acidentais, ou seja, são introduzidos e decididos ad hoc (idem, p. 90).

Enfim, as diferentes tradições sócio-políticas de dois municípios não se refletem de maneira muito significativa na configuração da participação social dos conselhos de saúde, que, em geral, são caracterizados pela baixa freqüência às reuniões, pela predominância do seguimento governamental e pelo pequeno número de deliberações sobre questões realmente significativas.

Em Lagoa da Prata, a ligação dos representantes governamentais ao PT não significou maior autonomia dos conselhos. Na verdade, como se indicou anteriormente, há indícios de instrumentalização do conselho pelo Governo municipal, com o retraimento da participação de setores não ligados ao partido. Há certa distância entre o discurso em favor da democracia participativa e o pragmatismo exigido pela competição político-eleitoral. De alguma maneira, o partido utiliza-se da sua capacidade participativa como meio de consolidar seu poder político.

A própria avaliação que os conselheiros fazem dos conselhos deixa bastante a desejar. Em Lagoa da Prata, 28\% dos conselheiros acham que o conselho democratiza a política municipal de saúde e, em Bom Despacho, apenas 7\% compartilham da mesma opinião (idem, p. 108). Apesar da diferença significativa de avaliação entre os municípios, a percepção dos conselhos, como instrumento de democratização é bastante decepcionante.

Apesar disso, se comparada com a forma burocrática e centralizada de gestão da saúde até meados dos anos 1980, e a despeito dos problemas apontados acima, a mera regularidade do funcionamento dos conselhos, mesmo sob a predominância do segmento governamental, garante certa publicidade às questões relativas à gestão pública da saúde e justifica a aposta cautelosa de que esses espaços de participação possam instaurar um círculo virtuoso de democratização e geração de capital social, possibilitando a formação política e qualificação técnica de agentes da sociedade civil.

\section{2 O Projeto CEIA}

Outra experiência de implementação de espaços participativos, talvez a única no caso brasileiro, foi o projeto Centro de Encontro e Integração de Ações (CEIA), desenvolvido no município de Betim, de 1997 a $2000^{7}$. O projeto foi implementado por um governo do Partido dos Trabalhadores, com o objetivo de aprimorar a participação política dos moradores de Betim por meio da constituição de canais de participação da população junto ao poder público municipal.

O município de Betim é um dos mais ricos do estado de Minas Gerais, sede de dezenas de empresas industriais, algumas importantes, como a fábrica de automóveis Fiat e a Petrobrás. É, por exemplo, o segundo pólo automobilístico do país e a segunda maior arrecadação de Imposto sobre Circulação de Mercadorias e Serviços (ICMS) do estado de Minas Gerais. Com cerca de 330000

7 Esse tópico baseia-se nos dados levantados em Lima (2003). 
habitantes, situa-se na região metropolitana de Belo Horizonte. É um município com $97 \%$ de população urbana. Como toda grande cidade brasileira, tem problemas sociais agudos como pobreza e falta de segurança pública.

Talvez por combinar uma população composta por uma massa de pobres e um operariado industrial, a cultura política do município apresenta traços contraditórios. De um lado, apresenta manifestações de patrimonialismo e clientelismo; de outro, a presença de uma sociedade civil organizada, com movimentos sociais de diversos tipos, sindicatos atuantes e a atuação de uma Igreja Católica progressista. Essas características diferenciadas expressam-se na alternância entre dois grupos, ideologicamente distintos, no governo do município: um à direita, mais clientelista; e outro à esquerda, mais programático e conectado aos setores organizados da sociedade.

A experiência abordada aqui, como se disse, foi desenvolvida no contexto de um governo do Partido dos Trabalhadores (PT), que, em coligação com o Partido Comunista do Brasil (PC do B), o Partido Socialista Brasileiro (PSB) e o Partido Verde (PV), governou a cidade de 1993 a 2000.

Expressando essa origem de esquerda do governo municipal, o projeto CEIA foi inspirado nos Comitês de Defesa da Revolução cubanos. A idéia do projeto surge de uma visita do Prefeito de Betim a Cuba, especificamente de seu contato com os comitês. Assim, tal como a experiência cubana, o CEIA buscou organizar a população de Betim em núcleos por quarteirões, no sentido de mobilizá-la para discutir questões referentes aos serviços públicos. Cada quarteirão foi incentivado, pelo governo municipal, a eleger seus representantes e seus suplentes, cujo papel seria intermediar as relações entre os moradores do município e o poder público. Cerca de $90 \%$ dos quarteirões da cidade chegaram a constituir seus representantes. Em julho de 2000, o projeto contava com 4456 representantes de quarteirões, entre titulares e suplentes, englobando 97 bairros e 300000 habitantes (LIMA, 2003, p. 93). Ou seja, quase a totalidade dos habitantes do município.

O poder Executivo municipal fomentou a organização da população em torno de cada quarteirão, com o objetivo declarado de superar os traços clientelistas que caracterizariam a cultura política da cidade. O projeto surgiu da percepção dos governantes de Betim de que os mecanismos da democracia representativa seriam insuficientes para uma manifestação realmente democrática da população, percepção esta, como vimos, bastante difundida nos setores de esquerda. Além disso, radicalizando essa tendência, diagnosticavam que os mecanismos já existentes de participação política da sociedade civil, quais sejam, o orçamento participativo e os conselhos de políticas setoriais, não estavam conseguindo envolver a maioria dos cidadãos, demonstrando fragilidade em complementar a democracia representativa. Daí a necessidade de expandir os canais de participação.

A adoção do CEIA torna-se, portanto, prioridade do governo do PT, ao lado da priorização de políticas sociais como saúde, educação, emprego. Com a ênfase em consolidar canais de participação da sociedade civil junto ao poder público, o projeto CEIA torna-se central para a estratégia do governo de consolidar a democracia participativa no município. Um processo, diga-se de passagem, que já estava em desenvolvimento. No governo anterior, do mesmo PT, espaços de participação como orçamento participativo, gestão participativa das escolas, conselhos deliberativos de políticas públicas e Plano Diretor elaborado de maneira participativa haviam sido implementados. Imaginava-se, como no resto do país, que com a capacidade de mobilização desenvolvida como reação ao regime autoritário por amplos setores da sociedade civil brasileira - no caso do município, especialmente o operariado industrial -, bastaria a criação desses canais de participação para que a democracia participativa desenvolvesse todo o seu potencial.

Porém, os resultados alcançados, no primeiro momento, ficaram aquém do almejado. O Plano Diretor, com prazo de vigência de 15 anos, foi discutido com a população por meio das oito regiões administrativas da cidade, mas não conseguiu mobilizar suficientemente a população, talvez por ser uma política regulatória cujos efeitos seriam pouco percebidos pela maioria, por se fazerem sentir no longo prazo. $\mathrm{O}$ orçamento participativo, apesar da participação expressiva no seu início, começou a se esvaziar pela escassez de recursos para cumprir as obras definidas pela população. Os conselhos de políticas setoriais foram criados, mas também apresentavam problemas em seu funcionamento. O governo municipal acabava tendo controle sobre eles, comprometendo o seu objetivo de controle social. No geral, os conse- 
lhos faziam poucas reuniões e, na prática, o seu caráter era mais consultivo do que deliberativo. Funcionavam, na verdade, segundo o interesse do poder Executivo. Além do mais, percebeu-se que a população mais jovem não participava em nenhum desses canais de deliberação.

Sendo assim, partindo da percepção das insuficiências dos mecanismos participativos então existentes, o projeto estabeleceu níveis de organização, partindo, primeiro, do CEIA por quarteirões, cujos representantes reuniam-se uma vez por mês com membros do governo municipal; num segundo nível, com representantes do CEIA por bairros; num terceiro nível, por regiões administrativas; finalmente, com a representação de todos os CEIAs do município. Assim, as atividades organizavam-se nos quarteirões, de acordo com um planejamento definido de maneira participativa e iam se agregando por bairros, regiões administrativas, até alcançarem todo o município. Mensalmente havia reuniões por bairros. Trimestralmente, os representantes regionais reuniam-se com o Prefeito e seus secretários. Finalmente, havia um encontro festivo anual com todos os representantes da cidade, que chegou a reunir mais de 3000 pessoas.

A equipe de trabalho da prefeitura municipal foi organizada em uma coordenação geral, uma equipe interna, de apoio logístico, e uma equipe externa, de trabalho de campo. O coordenador geral do projeto ganhou status de Secretário $\mathrm{Mu}-$ nicipal, estando vinculado diretamente ao gabinete do Prefeito. A equipe externa trabalhava nas regionais administrativas, com o objetivo de mobilizar a participação nos quarteirões e mediar a interlocução do governo com a comunidade. Essa equipe era formada por pessoas com atuação em cada regional e composta por militantes do Partido dos Trabalhadores - o que claramente revestia o projeto de um caráter partidário.

As reuniões e a escolha dos representantes de quarteirões eram organizadas pela prefeitura. Os representantes de quarteirões, que não tinham tempo estipulado de mandato, ganhavam carteira de identificação para facilitar seu acesso às autoridades municipais. Para atrair as pessoas para as reuniões, inicialmente foi colocada em discussão a política de saúde do município, tema constatado como prioritário para a população. Porém essa estratégia era eficiente especificamente com as classes populares, já que boa parte da classe mé- dia resolvia seus problemas de saúde por meio de seguros privados. Sendo assim, inseriu-se a discussão de um tema mais sensível para os setores médios da população: o problema da segurança pública. Para isso foi realizada uma parceria com a Polícia Militar do estado de Minas Gerais.

A estratégia de conectar os espaços de participação com a discussão de políticas públicas específicas parece ter tido resultados diferenciados. Com a saúde, começou a haver sobreposição de espaços de representação com os conselhos municipais de saúde. No caso da segurança pública, a parceria dos representantes de quarteirão com a Polícia Militar parece ter logrado algum êxito, na medida em que a mobilização potencializou a capacidade de ação da polícia.

Em suma, se as políticas de segurança e saúde foram formas de atrair participação, a orientação do Prefeito era de que todas as ações do governo deveriam passar pelo projeto CEIA. Como o projeto era organizado pelo gabinete do Prefeito, isso implicou em uma forte centralização das decisões no chefe do poder Executivo municipal. E esse poder de controlar as relações com a população do município foi utilizado como forma de limitar o espaço de ação política de outros grupos do próprio partido do Prefeito, que disputavam o controle da legenda com o seu grupo. Sendo assim, tal estratégia provocou reações de setores da própria administração: alguns secretários municipais rebelaram-se contra essa centralização, pois subordinava excessivamente as ações de suas pastas ao gabinete do Prefeito. E isso com a agravante, na perspectiva dos secretários, de que essa centralização vinha legitimada como expressão da participação dos cidadãos. Esse embate pela distribuição do poder expressou-se, por exemplo, no veto que os administradores regionais impuseram à idéia cogitada, no início do projeto, de formar conselhos populares para as administrações regionais $^{8}$. Os administradores regionais vetaram a idéia, já que em sua grande maioria, pretendendo candidatar-se a vereador, viam nesses conselhos espaços para atuação de lideranças rivais ligadas ao chefe do poder Executivo. Ou seja, o projeto influenciava na disputa de poder de grupos rivais dentro do próprio partido do governo.

${ }^{8}$ A administração municipal era dividida territorialmente em regionais administrativas, cada qual com seu administrador. 
Como se viu, pelo menos formalmente o CEIA consolidou-se em todo o município. Em avaliação realizada pela própria prefeitura, $56 \%$ dos representantes participavam assiduamente das reuniões (idem, p. 111) $)^{9}$. Buscando avaliar os motivos que levavam os $44 \%$ restantes a não participar, a prefeitura apurou que um deles estaria relacionado com o problema de falta de segurança pública. Como o horário mais viável para a participação das pessoas que trabalham é o noturno, justamente o mais perigoso, diversas pessoas declararam não participar das reuniões do CEIA por medo da violência. Justificativa que remete às pressões desmobilizadoras, apontadas por Whitehead (1999), a que a sociedade civil está sempre exposta, dentre elas a falta de segurança.

A incidência da questão de gênero no tema da participação, bastante evidente na bibliografia sobre o tema, faz-se notar no caso abordado. A maioria dos participantes do CEIA era de mulheres: $76,5 \%$, contra $23,5 \%$ de homens. A maior parte dessas, $57 \%$, estava na faixa etária situada entre 30 e 50 anos e $86 \%$ eram mães. A maioria, por sua vez, encontrava-se em condições desfavoráveis no mercado de trabalho: $45,4 \%$ declaravam-se desempregadas ou trabalhavam em casa - mais especificamente, $31 \%$ como trabalhadoras do lar, 5\% como costureiras e $14,5 \%$ com serviços eventuais. Essas mulheres tinham, em sua maioria, baixa renda: $46 \%$ ganhavam até dois salários mínimos e $86,5 \%$, até cinco salários. Tinham também baixo grau de educação formal: $71,9 \%$ haviam cursado até o ensino fundamental (LIMA, 2003, p. 115-120).

Portanto, dada a precariedade de sua inserção no mercado de trabalho formal, a maioria dos participantes do CEIA tinha disponibilidade de tempo para participar, solucionando um outro fator desmobilizador bastante relevante nos tempos atuais: a disponibilidade de tempo para o exercício da participação democrática. No caso de Betim, porém, o requisito "disponibilidade de tempo" está presente de uma forma perversa: mulheres excluídas do mercado de trabalho formal, de baixa formação educacional e pobres são as que mais participam. Talvez por ser a única saída que lhes restava para resolver seu problema de sobrevivên-

\footnotetext{
9 Os dados foram levantados por meio de entrevistas com cerca de 1700 representantes de quarteirões, realizadas em abril de 2000 (LIMA, 2003).
}

cia. Nesse ponto, pode-se sugerir a hipótese de que a democracia participativa caracteriza-se, não raro, pela participação de excluídos em decisões secundárias: as grandes questões seriam, essas sim, decididas em espaços insulados por grupos de interesses com acesso a recursos de poder mais efetivos.

O caso do projeto CEIA fornece elementos para outro tipo de questão bastante relevante na discussão sobre participação democrática. Deslocando o foco para uma perspectiva mais ampla, uma questão crucial a ser enfrentada, nesse tema, é qual o resultado da adoção de uma diversidade de experiências participativas simultaneamente. Nesse sentido, havia a preocupação, pelo menos manifesta, dos formuladores do projeto CEIA, em não concorrer com outros canais de participação existentes, como os conselhos setoriais de políticas públicas e o orçamento participativo. De qualquer forma, apesar dessa intenção expressa, estava no horizonte dos formuladores do projeto a idéia de que quanto mais espaços de participação difundissem-se, mais consolidada estaria a cidadania democrática. Na prática, o que se viu foi uma sobreposição de espaços participativos concorrendo entre si. Algo que não é processado adequadamente pelos formuladores de reformas institucionais é que a profusão desses espaços, de alguma maneira, e em alguns casos específicos, implica sobreposição e concorrência. Sendo assim, ao contrário das esperanças de muitos, a difusão além de certo limite desses espaços pode prejudicar a qualidade de participação. O caso de Betim, que não é exceção, demonstra que não há um planejamento global de articulação desses espaços. Na verdade, eles vão se constituindo a partir de demandas parciais e fragmentadas, cuja agregação produz "efeitos não esperados". Mesmo porque, como constatado no caso em questão, as pessoas atuantes apareciam participando em diversos espaços ao mesmo tempo. Ou seja, em Betim, o aumento dos espaços de participação não implicou necessariamente acréscimo na quantidade e na qualidade da participação democrática.

Uma evidência dessa sobreposição de espaços de participação e dos conflitos decorrentes foi a reação negativa das associações de moradores do município ao CEIA, já que se viram ameaçadas pelo projeto e buscaram estratégias para garantir sua autonomia em relação ao governo municipal, boicotando a participação nos quarteirões, em al- 
guns casos, ou buscando eleger os seus representantes, em outros casos. Houve aí claramente uma disputa de controle de espaços sobrepostos entre grupos ligados ao poder público e outros atores representados na sociedade civil.

De alguma forma, o potencial de conflito de interesses do projeto era do conhecimento dos seus formuladores. Seja com setores da sociedade civil, como no caso das associações de moradores do município, seja com o próprio poder Legislativo, como se verá. Tanto que o projeto CEIA foi concebido em sigilo pelo núcleo do poder municipal e implementado de maneira rápida, "para que os vereadores não manipulassem as reuniões de escolha dos representantes de quarteirão", segundo palavras do Prefeito de então (idem, p. 121). Mesmo assim, em resposta, os vereadores buscaram cooptar os representantes de quarteirão como cabos eleitorais, com muitos deles inclusive passando a assessorá-los. Em outros casos, vários vereadores alegaram que os representantes de quarteirão estavam usurpando suas funções ao mediar as demandas da população diretamente com o poder Executivo municipal.

Assim, havia o risco de instrumentalização da participação tanto pelo poder Executivo como pelo Legislativo. A idéia de uma complementação virtuosa entre os diversos espaços de participação deliberativa e entre a democracia participativa e a democracia representativa não se mostrou tão fácil no caso.

$\mathrm{Na}$ verdade, o objetivo dos formuladores do CEIA era dúbio. Ao mesmo tempo em que demonstraram acreditar na mobilização da população como meio de construção da democracia, pragmaticamente trabalharam no sentido de aumentar a base social de sustentação do governo, instrumentalizando a experiência do CEIA, com o objetivo de fortalecimento eleitoral do grupo no poder. Isso fica claro, por exemplo, na forma de organização da reunião anual com todos os representantes do projeto - um evento com forte conotação eleitoral, com a escolha de militantes do PT para mediar os contatos com os representantes de quarteirão e com o controle direto do gabinete do Prefeito na coordenação geral do projeto. Buscavam mais que se abrir às reivindicações da população: buscavam difundir as ações da prefeitura e arregimentar apoios políticos. E aqui, lançando um olhar mais realista aos fatos, pode-se afirmar que a democracia representativa, com sua lógica competitiva, estabelece inevitavelmente o perigo da instrumentalização da participação para fins eleitorais.

Outro aspecto a que o caso de Betim pode fornecer elementos de análise diz respeito à questão de em que medida tais experiências de participação dependem da vontade dos governantes. Com a alternância posterior do governo municipal, derrotados os partidos de esquerda comprometidos com a democracia participativa pelo grupo político do município mais à direta, nas eleições municipais de 2000, essas experiências refluíram: o CEIA e o orçamento participativo acabaram e os conselhos setoriais de políticas públicas passaram a ser desconsiderados pelos novos governantes. Com o Partido Liberal (PL) no poder, reforçaramse as relações abertamente clientelistas entre população e poder municipal. Há, assim, forte evidência da dependência que as experiências de democracia participativa têm do poder Executivo, sustentando a tese de que o capital social deriva, de maneira significativa, do comprometimento do poder público com a idéia da participação.

\section{CONSIDERAÇÕES FINAIS}

Enfim, em referência ao que foi desenvolvido até aqui, podemos retomar algumas reflexões sobre o esforço de consolidação de espaços de participação e deliberação da sociedade civil sobre as políticas públicas, nos anos recentes. Cremos que as observações que se seguem, ainda que incipientes e sustentadas em evidências insuficientes, podem ajudar a pensar sobre os problemas envolvidos no desafio da construção democrática.

Topicamente, podemos ressaltar que: 1) As experiências de participação abordadas demonstram a importância relativamente maior do papel do poder público e do compromisso de seus dirigentes com os espaços de participação, em relação às características da sociedade civil. O papel mobilizador do Estado é fundamental para o sucesso das iniciativas de participação. As diferentes características das sociedades civis de Lagoa da Prata e Bom Sucesso não são suficientes para explicar um menor ou maior sucesso dos conselhos de saúde. Por outro lado, concretamente, a mudança na orientação do governo municipal de Betim, no sentido do seu não comprometimento com a democracia participativa, implicou refluxo das diversas experiências de participação social no município; 
2) A afirmação de que as mulheres têm maior propensão a participar mostrou-se verdadeira nos casos abordados, mas não por características "ontológicas" do gênero feminino. Essa tendência explica-se por fatores como maior tempo disponível, dada a sua exclusão do mercado formal de trabalho, e necessidade de resolverem seus problemas pelas vias disponíveis;

3) A relação positiva, proposta por parte considerável da literatura sobre o tema, entre maior nível educacional e de renda e maior disposição de participar não é confirmada em todos os casos abordados neste trabalho. Os espaços da democracia participativa são utilizados majoritariamente por grupos com baixa renda e escolaridade. Isso suscita a questão, reiterada aqui, de se esses espaços de participação seriam para os setores desprivilegiados da sociedade, enquanto as elites atuariam de maneira mais eficaz por meio de canais menos transparentes;

4) Capital social é algo que pode ser realmente afetado pelo que Whitehead (1999) chama de "externalidades", como disponibilidade de tempo e condições de segurança pública. Ou seja, a falta de segurança, tão comum nas grandes cidades, e o tempo escasso funcionam como um fator desmobilizador;

5) Maior capital social pode ser, em alguns casos, negativo para a democracia: a existência de grupos com grande capacidade de mobilização pode representar a captura dos espaços de decisão em detrimento de outros grupos. É o caso, por exemplo, do conselho de saúde de Lagoa da Prata, instrumentalizado pelo PT, como resultado de sua relativa maior capacidade participativa;

6) Compatibilizar democracia representativa com democracia participativa não é algo tão sim- ples. A lógica da competição eleitoral acaba contaminando os espaços de participação. A instrumentalização desses espaços para fins político-eleitorais deve-se tanto ao poder Executivo quanto ao Legislativo. Isso é bastante claro na experiência do CEIA, mas também está presente na experiência do conselho de saúde de Lagoa da Prata;

7) Além disso, tomando como referência o caso de Betim, não há uma visão de conjunto sobre a institucionalidade democrática. Os espaços de participação são criados de forma pontual e fragmentada, redundando em conflitos e sobreposições. Parece não bastar a difusão desses espaços para a "democracia se democratizar". Há que existir uma compatibilização desses espaços, considerando uma medida equilibrada entre potencial participativo de dada sociedade e os espaços participativos disponíveis;

8) Enfim, uma nota otimista. No geral, o grau de participação efetivamente verificado está aquém do desejado pelos defensores da democracia participativa, já que o critério de medida geralmente adotado é um padrão ideal difícil de ser concretizado. No entanto, se olhamos a trajetória histórica recente das nossas instituições democráticas, apesar dos seus problemas, a definição de espaços de deliberação pela sociedade civil tem potencial inegável de aumentar a accountability do poder público, aumentando a transparência de suas ações. Mas a consolidação desses espaços não é solução para tudo. $\mathrm{O}$ tema deve ser tratado, portanto, dentro de suas possibilidades reais. Não deve substituir, por exemplo, a crítica necessária, e hoje relegada ao segundo plano, da lógica excludente dos macro-processos políticos, sociais e econômi$\cos$.

Carlos Vasconcelos Rocha (carocha@pucminas.br) é Doutor em Ciências Sociais pela Universidade Estadual de Campinas (Unicamp) e Professor da Pontifícia Universidade Católica de Minas Gerais (PUC-MG).

\section{REFERÊNCIAS BIBLIOGRÁFICAS}

ABU-EL-HAJ, J. 1999. O debate em torno do capital social: uma revisão crítica. Boletim Informativo Bibliográfico, São Paulo, n. 48, p. 65-79.
ARRETCHE, M. 1996. Mitos da descentralização. Mais democracia e eficiência nas políticas públicas? Revista Brasileira de Ciências Sociais, São Paulo, v. 11, n. 31, p. 44-66, jun. Dis- 
ponível em: http://www.anpocs.org.br/portal/ publicacoes/rbcs_00_31/rbcs31_03.htm. Acesso em: $20 . \mathrm{dez} \cdot \mathbf{2 0 1 0 .}$.

BOSHI, R. 1987. A arte da associação: política de base e democracia no Brasil. São Paulo: Vértice. COLEMAN, J. 1988. Social Capital in the Creation of Human Capital. American Journal of Sociology, Chicago, v. 94, p. 95120.

DAGNINO, E. 2002. Sociedade civil e espaços públicos no Brasil. Rio de Janeiro: Paz e Terra.

EVANS, P. 1996. Government Action, Social Capital and Development: Reviewing the Evidence on Synergy. World Development, Montreal, v. 24, n. 6, p. 1119-1132, June.

GRAVATÁ, H. 1982. Contribuição bibliográfica sobre Belo Horizonte. Revista do Arquivo Público Mineiro, Belo Horizonte, v. 33.

LIMA, J. 2003. Construindo a democracia: mecanismo de participação política da Prefeitura de Betim - 1997 a 2000. Belo Horizonte. Dissertação (Mestrado em Ciências Sociais). Pontifícia Universidade Católica de Minas Gerais.

OLIVEIRA, A. 2005. Luzes e sombras da participação social na gestão pública municipal.
Belo Horizonte. Dissertação (Mestrado em Ciências Sociais). Pontifícia Universidade Católica de Minas Gerais.

PUTNAM, R. 1996. Comunidade e democracia: a experiência da Itália moderna. Rio de Janeiro: Fundação Getúlio Vargas.

SANTOS, B. 2002. Democratizar a democracia: os caminhos da democracia participativa. Rio de Janeiro: Civilização Brasileira.

TATAGIBA, L. 2002. Os conselhos gestores e a democratização das políticas públicas no Brasil. In: DAGNINO, E. (org.). Sociedade civil e espaços públicos no Brasil. Rio de Janeiro: Paz e Terra.

TENDLER, J. 1999. Mitos da reforma do Estado e a descentralização: conclusões de um estudo de caso no Brasil. In: MELO, M. (org.). Reforma do Estado e mudança institucional no Brasil. Recife: Massangana.

WHITEHEAD, L. 1999. Jogando boliche no Bronx: os interstícios entre a sociedade civil e a sociedade política. Revista Brasileira de Ciências Sociais, São Paulo, v. 14, n. 41, p. 1530. Disponível em: http://www.scielo.br/pdf/ rbcsoc/v14n41/1749.pdf. Acesso em: 20.dez.2010.

\section{OUTRAS FONTES}

BRASIL. 1990. Lei $n .8142$, de 28 de dezembro de 1990. Disponível em: http:// www.planalto.gov.br/ccivil_03/Leis/ L8142.htm. Acesso em: 20.dez.2010.

FUNDAÇÃO GETÚLIO VARGAS. 2010. Sítio eletrônico. Disponível em: http:// inovando.fgvsp.br/conteudo/publicacoes/ index.htm. Acesso em: 20.dez.2010.

\section{INSTITUTO BRASILEIRO DE GEOGRAFIA}

E ESTATÍSTICA. 2000. Censo demográfico 2000. Disponível em: http://www.ibge.gov.br/ home/estatistica/populacao/censo2000/ default.shtm. Acesso em: 20.dez.2010. 
PUBLIC MUNICIPAL MANAGEMENT AND DEMOCRATIC PARTICIPATION IN BRAZIL

Carlos Vasconcelos Rocha

This article looks at three cases of democratic participation in municipal administration in the state of Minas Gerais, that is, Health Management Councils (Conselhos Gestores de Saúde), in the Bom Despacho and Lagoa da Prata municipalities, and the Centers for Meetings and Integrating Actions (Centros de Encontro e Integração de Ações (CEIA)), in the municipality of Betim. Over the last few decades, political participation has been characterized by a growing presence of civil society in processes surrounding the definition of public policy. Thus, the spaces in which civil society and State actors participate in diverse arenas of decision-making on social policies tend to become institutionalized. A substantial part of the existing literature places its wager on the democratic virtues of political participation. This article, however, attempts to point to a series of problems affecting the institutionalization of democratic participation. Results of the cases we look at here show that the experiments analyzed do not indicate the evolution of Brazilian democracy in the direction of its initial promise. In general, the degree of participation that is verified is less than that which defenders of participatory democracy would desire, especially since the measurement criteria that are adopted reflect an ideal standard that does not materialize easily. Nonetheless, if we look at the recent historical trajectory of our democratic institutions, the definition of civil society's deliberative spaces, in spite of its problems, has the undeniable potential of reinforcing the accountability of public power, thus increasing the transparency of its actions.

KEYWORDS: Democratic Participation; Municipal Administration; Public Policy. 


\section{L'ADMINISTRATION PUBLIQUE MUNICIPALE ET LA PARTICIPATION DEMOCRATIQUE AU BRESIL}

\section{Carlos Vasconcelos Rocha}

Ce travail aborde trois cas de participation démocratique dans les administrations municipales de Minas Gerais: les Conseils Gestionnaires de Santé, dans les villes de Bom Despacho et Lagoa da Prata, et les Centres de Rencontre et Intégration d'Action (CEIA), dans la ville de Betim. Dans les dernières décennies, la participation politique a été marquée par une croissante présence de la société civile dans la définition des politiques publiques. Ainsi, sont institutionnalisés des espaces où des acteurs de la société civile et d'Etats participent dans des nombreux domaines de décision de politiques sociales. Partie substantielle de la littérature, ajoutée aux vertus démocratiques de la participation. Ce travail, toutefois, vise à identifier une série de problèmes qui affectent l'institutionnalisation de la démocratie participative. Les résultats des cas ici abordés, démontrent que les expériences analysées n'indiquent pas une évolution de la démocratie brésilienne, selon les promesses initiales. En général, le degré de participation effectivement vérifié est au-deçà de celui désiré par les defenseurs de la démocratie participative, puisque le critère de mesure généralement adopté est un standard idéal difficile a être atteint. Cependant, si nous observons la trajectoire historique récente de nos institutions démocratiques, la définition d'espaces de délibération par la société, malgré ses problèmes, a un potentiel indéniable de renforcer la reddition de comptes du pouvoir public, en augmentant la transparence de ses actions.

MOTS-CLES: démocratie participative; administration municipale; politiques publiques. 